\title{
DRÁCULA, UN ACERCAMIENTO A LA CARACTERIZACIÓN DEL PERSONAJE VAMPÍRICO: PERSPECTIVAS NARRATOLÓGICAS
}

\author{
Ana Isabel Bonachera García \\ Universidad de Almería \\ anais_7_3@hotmail.com
}

Recibido: 11-01-2016

Aceptado: 03-10-2016

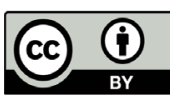

RESUMEN

Este artículo aborda los siguientes presupuestos básicos: a) exposición de las formas de caracterización del personaje vampírico en su expresión literaria, partiendo de una novela famosa que ha sido objeto de numerosos artículos y libros académicos, Drácula de Bram Stoker (obra maestra del género vampírico); y b) análisis detallado de los diferentes procedimientos de caracterización que atañen a este ser transgresor, todo ello acompañado de las más importantes ejemplificaciones (citas literarias).

Palabras clave: Drácula, caracterización, personaje vampírico, narratología.

\section{Abstract}

This article deals with the following basic presuppositions: a) exposition of the modes of characterisation of the vampire character in its literary expression, beginning with one famous novel that has been the subject of numerous scholarly article and books, Bram Stoker's Dracula (the masterpiece of the vampire genre); and b) detailed analysis of the different characterisation processes attached to this transgressive being, all accompanied by the most important examples (literary quotations).

KeYwORDs: Dracula, characterisation, vampire character, narratology.

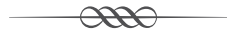




\section{INTRODUCCIÓN}

Año 1897, en la Inglaterra victoriana tendría lugar el nacimiento de la obra que encarnaría la esencia misma del vampirismo hasta el punto de transformarse en el epítome del personaje más popular que, incluso hoy en día, continúa siendo un mito que alcanza el grado de universalidad: Drácula, del escritor irlandés Bram Stoker. ${ }^{1}$

La literatura se ha encargado de popularizar un tipo específico de vampiro, como el destacado vampiro creado por John William Polidori en su relato de «El Vampiro»² (1819), Lord Ruthwen, cuya caracterización elaborada y su relación física y psicológica con la víctima le hizo ganarse a un número considerable de seguidores e inspirar novelas y relatos cortos tales como «Berenice» (1835), de Edgar Allan Poe, «La familia del Vourdalak» (1839), de Aleksei Tolstoi, Varney el Vampiro o El festín de sangre (1845) de James Malcolm Rymer, «Carmilla» (1872), de Joseph Sheridan Le Fanu, y Drácula (1897), de Bram Stoker.

A la altura de 1872, destaca la aparición de la figura de una mujer vampiro en la obra «Carmilla», del escritor irlandés Le Fanu. Se trató, pues, de un auténtico relato vampírico protagonizado por dos mujeres: Carmilla, una vampiresa, y Laura, su víctima. Esta última es quien, a través de un filtro delicado y tierno, expone los hechos acontecidos, afrontando temas tabú relacionados con la sexualidad, como el lesbianismo, el despertar sexual y la identidad emocional.

Sin embargo, no es hasta la publicación de la célebre y magistral obra de Stoker, Drácula, que la figura del vampiro se consolida definitivamente dentro de la literatura. El principal mérito de la novela de Stoker radica en la agudeza de dicho escritor para crear un mito deslumbrante, cuyas formas varían según la época, materializando todas sus representaciones en una figura evocadora y pintoresca que muestra no solo las inquietudes de su tiempo sino también algo que es a la vez monstruoso y humano, algo que, de una manera u otra, siempre nos ha turbado y que todavía nos preocupa.

1. Aunque bien es cierto que dicha popularidad a escala mundial se debe principalmente a su éxito en los mass media. Su primer empujón en éxito de popularidad se produjo en junio de 1924, tras su primera adaptación al teatro a cargo de Hamilton Deane. El impacto teatral impulsaría la difusión del libro, abriéndole las puertas para el cine, y de este a otros medios de difusión como la música, las series de televisión, los cómics, etc.

2. "Polidori's tale was in essence the first "vampire story", drawing on elements that were present in folklore, to which were added other ideas, such as the vampire being an aristocratic member of society, that would become central to all later vampire stories» (Beresford, 2008: 116). El trabajo de Polidori resultó ser una de las obras de horror más influyentes (Skal, 2006: 37) o incluso la historia de horror más influyente de todos los tiempos y la primera historia que logró fusionar con éxito los disparatados elementos del vampirismo en un género literario coherente (Frayling, 1991: 106-108). 
La documentación que Stoker recopiló para la gestación de Drácula (Notes and Data For His Dracula, que ahora se encuentran en la Rosenbach Foundation de Filadelfia desde 1973) demuestra que llevó a cabo una profunda investigación. Su conocimiento acerca del folclore y las supersticiones de Transilvania lo obtuvo a raíz de un artículo de Emily Gerard, «Transylvanian Superstitions», publicado en el volumen 18 de The Nineteenth Century, en 1885. No obstante, también aprendió todo acerca de los hombres lobo en el libro The Book of Were-Wolves, Being an Account of a Terrible Superstition (1869), de Sabine Baring-Gould; y en Account of the Principalities of Wallachia and Moldavia (1820), de William Wilkinson, Stoker pudo toparse con el nombre de «Dracula».

Las historias de Varney y «Carmilla» resultaron ser una gran fuente de inspiración. Aparte de estas dos influencias mayores, y de la Biblia (cuyas referencias a esta aparecen a lo largo de la novela), existe un amplio abanico de plausibles y verosímiles fuentes literarias, como la Historia de gentibus septentrionalibus (1555), de Olaus Magnus, Macbeth (1611), de William Shakespeare, «La muerta enamorada» (1836), de Théophile Gautier, «Los montes Cárpatos» (de Los mil y un fantasmas, 1849), de Alejandro Dumas, «The Mysterious Stranger» (ca. 1860), de autor anónimo, Lokis (1868), de Prosper Mérimée, Ella (1887) de Henry Rider Haggard, The Witch of Prague (1891), de Francis Marion Crawford, «El parásito» (1894), de Arthur Conan Doyle, y La rama dorada (1890), de James George Frazer.

Mas Stoker no se limitó exclusivamente a copiar los numerosos antecedentes literarios o el folclore balcánico, sino que también remodeló todo el material extraído de sus lecturas, creando un perfil del vampiro bastante original. El vampiro stokeriano se mueve por puro instinto, puede ver en la oscuridad (e incluso atravesar la espesa niebla), es enormemente fuerte (a pesar de que no necesita comer ni beber como los seres humanos, al igual que el protagonista de Varney el vampiro), tiene poder sobre los seres de la noche (como las ratas, el murciélago, los lobos, etc.), muestra una actitud ambivalente ante los objetos religiosos (solo le afectan las reliquias más antiguas), tiene un «colmillo blanco» que puede acortar o alargar a voluntad, no proyecta sombras, no se refleja en los espejos y necesita ser invitado por alguien para poder entrar en un hogar habitado.

En nuestra exploración sobre las diversas formas y técnicas de caracterización del personaje vampírico, tomaremos como punto de apoyo para nuestra investigación la novela Drácula, puesto que es indiscutible su éxito y aportación al género gótico (pues no hubo otro trabajo igual tras la publica- 
ción de la exitosa novela Melmoth el errabundo de Charles Robert Maturin, publicada en 1820), y en especial al género vampírico, y a otros mass media.

FORMAS DE CARACTERIZACIÓN DEL PERSONAJE VAMPÍRICO EN LA NOVELA DRÁCULA DE BRAM STOKER

El conde Drácula encarna a un ser sobrenatural de naturaleza perversa, un no muerto, que bebe sangre humana, «a pariah among the fiends» (Summers, 1960: 6). A pesar de ser una criatura abominable, no por ello deja de ser irresistiblemente atractivo, pues nos hace caer en una especie de dulce ensoñación, entregándonos al delirio del éxtasis y de la pasión.

Boris Tomashevski (1978: 222) definió el proceso de caracterización del personaje como un «un procedimiento que sirve para reconocerlo. Se (...) entiende por característica los motivos que definen el alma y el carácter del personaje», es decir, la caracterización es un "proceso de atribución a los personajes, en el discurso o el relato, de una serie de rasgos y atributos, físicos y/o psicomorales» (Valles, 2008: 169). Un análisis detallado del aspecto exterior (prosopografía) e interior o psíquico-moral (etopeya) de este ser ficticio nos servirá para lograr un retrato (o effictio) aproximado de la bestia.

La caracterización del personaje central, Drácula, y de las vampiresas se suele bifurcar en las dos formas típicas de caracterización, a saber, directa e indirecta. La caracterización directa viene dada por la descripción de los atributos físicos, psíquicos y ético-morales de los personajes sobrenaturales, la cual es presentada con la suficiente exhaustividad para que queden retratados perfectamente los personajes en cuestión y entender, por tanto, sus cambios y comportamientos en el devenir de los acontecimientos. Este procedimiento de caracterización se erige dentro del discurso narrativo con este único objetivo determinador del universo singular del personaje vampírico. Asimismo, la información la filtran otros personajes de la historia, los personajes-narradores, hallándonos ante una heterocaracterización. En este caso, la información dada es subjetiva, pues está condicionada por el «campo visual» del personaje-narrador, quien refleja la conducta y palabras del personaje descrito (también puede acudir a otras fuentes como los documentos encontrados, los testimonios de terceros, etc.). «La imagen final del personaje depende en este caso no tanto de la disponibilidad e información, sino, en especial, de la "actitud" de narrador hacia él» (Garrido, 1996: 90).

En cuanto a la caracterización indirecta, las conversaciones, los gestos e incluso los tics pueden desempeñar un papel notorio, pues acentúan los ras- 
gos que merecen ser evidenciados (Reis, 1996: 34). Las acciones, reacciones, gestos, indumentaria (totalmente negra), lugar de residencia (el castillo siniestro y en ruinas de los Cárpatos), etc. del conde y de las vampiresas son otra forma de caracterizarlos; la descripción exhaustiva de Drácula en el capítulo XV de la novela no hace sino confirmar lo que el lector ha ido deduciendo, por medio de los relatos subjetivos de los personajes-narradores, según avanzaba la historia.

También es importante destacar la relación que existe entre los atributos de los personajes y el espacio en que se mueven (Reis, 1996: 34). Existe una interrelación caracterización-espacialización que podemos reconocer en las distintas transformaciones (a nivel físico, psíquico y moral) por las que pasa el conde, desde que sale del castillo de Transilvania (Drácula se presenta ante Jonathan Harker como un cochero con capacidades sobrehumanas y como un ominoso conde), viaja en barco hasta Inglaterra (transformado en un lobo al desembarcar en Whitby) y se instala en el nuevo país (el conde se transforma en un joven, atractivo y distinguido aristócrata). Todo ello no es sino una muestra más de su indiscutible capacidad para adaptarse, sobrevivir y llevar a cabo sus ambiciosos planes de conquista. ${ }^{3}$

La cuestión de la voz es otro factor importante a tener en cuenta, pues «según el tipo de narrador, las caracterizaciones de los personajes oscilarán entre una serie de niveles que irán desde el distanciamiento hasta la caracterización parcial, mediatizada o interesada» (Álamo, 2006: 199). En nuestro caso, nos encontraríamos ante un tipo de narrador homodiegético ${ }^{4}(\mathrm{o}$, mejor dicho, narradores homodiegéticos, puesto que son varios los personajes que filtran la información) quien, en primera persona (o intradiegético ${ }^{5}$ ) y mediante un uso personal del lenguaje, ya sea en forma de diarios, memorandos, periódicos, telegramas o cartas, marca enérgicamente ciertos rasgos de los personajes vampíricos por el registro subjetivo de una fijada focalización interna. Es, desde

3. Asimismo, podemos localizar esta interrelación de caracterización y espacio en la escena final eliminada en la que, al morir Drácula, el castillo se viene abajo. Esta escena posiblemente fue eliminada por el excesivo parecido con «La caída de la Casa Usher» (1839), de Edgar Allan Poe o, como sugiere Molina (1993: 30), debido a una decisión editorial de conservar el castillo para así, en un futuro, continuar con la historia.

4. Se trata de un narrador testimonial, pues aunque haya participado en los acontecimientos que relata, no tiene sin embargo un papel protagonista en la novela de Stoker sino más bien de mero testigo (o personaje secundario). El objetivo no es narrar la vida pasada de Mina, John, Quincey, etc., sino todo aquello que tiene que ver con el conde Drácula. De hecho, ya el mismo título de la obra es un indicador de cuál es el centro de atención narrativa; de tal manera que aun cuando los narradores nos relaten sus propias angustias sabemos, por la disposición paratextual del título, que será el relato del personaje al que se refiere el mismo: Drácula.

5. Tzvetan Todorov (1975: 83-84) afirma que la característica principal de las historias sobrenaturales es el uso de la voz en primera persona, lo que permite al lector identificarse con el personaje. 
esta perspectiva, como Stoker simultáneamente caracteriza al conde Drácula y lo singulariza y amolda en sus concepciones ideológicas de aristócrata infernal, astuto, ambicioso y sin escrúpulos, con una fuerza sobrehumana y una ávida sed de sangre. Es más, posiblemente uno de los mayores méritos de Stoker radique en esto, pues a pesar de que presenta a su villano al principio del relato y lo mantiene entre bastidores la mayor parte de la historia, materializándose al final de la novela, sin embargo, logra inundar por completo toda la narración. Entonces, son los personajes secundarios del relato in medias res (o exabrupto) quienes describen las atribuciones, tanto físicas como psíquico-morales, de los vampiros, prestando especial atención al protagonista (o anti-héroe), el conde Drácula.

Desde el principio, el narrador testimonial nos va presentando a un personaje con intriga creciente. Según avanza la historia, los narradores nos irán desvelando al personaje principal a partir de un punto de vista interno, por el que, progresivamente, el autor nos va a ir redondeando a este ente de ficción. Por tanto, la caracterización directa e indirecta de Drácula es de orden gradual y acumulativo.

\section{Procedimientos Singulares de CARACTERIZACión DEL PERSONAJE} VAMPÍrico EN LA NOVELA DRÁCULA, DE BRAM STOKER

En primer lugar, introduciremos la cuestión del nombre, puesto que adelanta con frecuencia las propiedades que le serán otorgadas más adelante (Ducrot y Schaeffer, 1998: 693; Reis, 1996). En la selección de la onomástica simbólica del nombre del protagonista, el autor lo relaciona con distintas facetas. Al examinar el nombre «Drácula», epíteto empleado en sentido despectivo con el significado de «demonio» (aunque originalmente fuera otro el significado $)^{6}$, aparecen diversos significados como «diablo», «ente sobrenatural», «espíritu que incita a hacer el mal», «ángel caído», «monstruo» o «ser dantesco», que, como veremos a lo largo de este estudio, encaja perfectamente con el aspecto psicológico del conde. Asimismo, la función del título epónimo es catafórica, puesto que le otorga al conde un papel primordial y

6. Vlad III también fue apodado «Dracula», que proviene del apodo que recibió su padre, Vlad Dracul (de la palabra latina draco, que significa «dragón»), miembro de la orden Societas Draconistrarum (Orden del Dragón). La orden utilizó como emblema un dragón envuelto en un círculo formado por su propia cola, cuyo extremo acababa enroscándose en su cuello. Es más que probable que la confusión en la traducción de Dracul como «dragón» radique en el significado de la palabra latina draco y en el emblema de la orden, puesto que el término rumano Dracul significa «diablo». La traducción exacta de «dragón» en rumano es balaur. 
planifica en parte nuestra lectura (introduce cuál va a ser la línea argumental de la obra). ${ }^{7}$ En líneas generales, podemos afirmar que el nombre denomina, determina y proyecta.

El antihéroe, Drácula, en ocasiones aparece caracterizado por un objeto que le pertenece, su forma de vestir o de hablar, y el lugar donde vive; estos están estrechamente adheridos a esta entidad, de manera que su aparición durante la narración apunta, aun in absentia, al sujeto del que son emblema. Oswald Ducrot y Jean-Marie Schaeffer (1998: 693) definen el emblema «como una identificación, a todos los niveles, de un actor determinado con las implicaciones espaciales $\mathrm{u}$ objetuales que enmarcan y definen su historia». «En un sentido más restringido, la descripción física de un individuo, los detalles de su indumentaria, algún gesto característico pueden ser considerados emblemáticos, es decir, significativos de la condición (por ejemplo, social), del carácter moral o de la psicología de los personajes» (Marchese y Forradellas, 1986: 117). La manera de vestir de Drácula, totalmente de negro, está en sintonía con su condición de ser sobrenatural de carácter lúgubre; igualmente, el castillo de los Cárpatos (herencia del castillo gótico que ya aparecía en El castillo de Otranto, publicada en 1764 por Horace Walpole) es fiel reflejo de los moradores pérfidos, longevos y majestuosos que habitan en él.

Stoker en ocasiones se refiere a Drácula en otros términos, como ordog (Satán), stregoica (bruja), vrolok y vlkoslak (hombre-lobo o vampiro), wampyr o nosferatu, ${ }^{8}$ que obedecen a las diversas facetas de un personaje caracterizado por su aspecto inicuo. Esta técnica de caracterización es conocida como aptronimia, la cual designa a partir de un rasgo característico del personaje. Con este concepto se «alude al antropónimo de un ser ficcional relacionado con alguna faceta de su personalidad, profesión o aficiones» (Valles y Álamo, 2002: 230).

Tomashevski (1978: 222) propone otra figura destacable: la máscara, definida como «la elaboración de motivos concretos que corresponden a la psicología del personaje, (...) un caso particular de caracterización indirecta. La descripción de la apariencia del personaje, de su indumentaria, de su habitación (...) puede considerarse como máscara». Las descripciones de las diversas manifestaciones físicas del conde concuerdan perfectamente con su perso-

7. Es importante señalar que la novela no se llamó Drácula hasta el último momento, seguramente por decisión editorial, puesto que el título original era Un-dead.

8. Adrien Créméné (1981: 244) emplea el término nosferat, resultado que deriva de una mala transcripción de la palabra necurat. Se trata de una especie de espíritu maléfico que puede transformarse en animales y cuyo nombre literalmente significa «el Inmundo». 
nalidad, o dimensión psicomoral interna, de aristócrata diabólico y cruel. Utilicemos, como ejemplo de la máscara, la descripción detallada de los documentos que Harker haya en la biblioteca del castillo, pues no solo arroja luz sobre las auténticas intenciones de Drácula, sino que también saca a relucir su verdadero yo (un ser perverso y codicioso que se prepara para llevar a cabo sus ambiciosos planes colonizadores en Inglaterra) que se esconde tras la fachada de un aristócrata culto y refinado:

En la biblioteca encontré, para gran alegría mía, un gran número de libros en inglés, varias estanterías llenas, y tomos encuadernados de revistas y periódicos. En el centro de la habitación había una mesa cubierta de revistas y periódicos ingleses, aunque ninguno de fecha muy reciente. Los libros trataban de los más diversos temas: historia, geografía, política, economía, botánica, geología, derecho, y todos ellos se referían a Inglaterra y a la vida, educación y costumbres inglesas. Había incluso libros de consulta como el Directorio de Londres, los libros «Rojo» $\mathrm{y}$ «Azul», ${ }^{9}$ el Almanaque de Whitaker, ${ }^{10}$ los Escalafones del Ejército y de la Armada, y el Directorio Legal, que por alguna razón especial me alegró ver (Stoker, 1993: 123).

Igualmente, el vocabulario del personaje, el estilo de su habla, los temas que le interesan, también pueden servirle de máscara (Tomashevski, 1980: 223). Durante las conversaciones mantenidas entre Harker y Drácula al comienzo de la historia, el personaje-narrador se percata del su perfecto dominio de la lengua inglesa, a pesar de que el conde insiste en asegurar que solo es un mero aprendiz. Con frecuencia se muestra cortés e impasible, aunque a veces muestra un particular interés y entusiasmo cuando se refiere a Inglaterra. Tras estas largas y excitantes charlas subyace una intención mucho más siniestra que aparentemente se oculta tras la imagen de boyardo refinado, neófito y anglófilo. El carácter apático de Drácula se ve fuertemente alterado cuando se refiere a su país, Transilvania, y relata su historia como si hubiese sido testigo real de todo lo que contaba. Drácula, mediante el uso de la analepsis y en primera persona (pues, «siempre que se refería a su linaje decía "nosotros" y utilizaba el plural como los reyes», Stoker, 1993: 137), relata el ilustre pasado de su regio abolengo. Su forma de relatar los hechos nos revela no solo que es longevo, pues realmente vivió en carne propia o fue testigo de lo que

9. El «Libro Rojo» incluía un listado completo de todas las personas que servían al Estado de Inglaterra o recibían algún tipo de subsidio, mientras que el «Libro Azul» registraba las sesiones del Parlamento británico.

10. Compilación que, aparte cumplir su función usual, contenía información sobre la demografía, el gobierno, las finanzas y el comercio británico. 
nos cuenta, sino que también posee un carácter férreo, una formación extraordinaria y una fuerza de voluntad absoluta:

Nosotros, los szekler tenemos derecho a sentirnos orgullosos, ya que por nuestras venas corre la sangre de muchas razas valerosas que se batieron como leones por defender su soberanía. (...) ¿Qué demonio o qué bruja fue tan importante como Atila, cuya sangre corre por estas venas? - y levantó los brazos-. ¿Es sorprendente acaso que fuéramos una raza de conquistadores, que fuéramos orgullosos, que cuando los magiares, los lombardos, los ávaros, los búlgaros o los turcos se lanzaron por millares sobre nuestras fronteras, les rechazáramos? ¿Es sorprendente que cuando Arpád y sus legiones asolaron la patria húngara, nos encontraran esperándoles en la frontera, y que allí concluyera las honfoglalas? ¿Y que cuando la oleada húngara se extendió hacia el este, los victoriosos magiares recurrieran a sus parientes los szekler, y durante siglos nos confiaran la vigilancia de la frontera con Turquía? Sí, y más todavía: el deber permanente de la vigilancia fronteriza, porque, como dicen los turcos, «el agua duerme y el enemigo vela». ¿Quién, entre las Cuatro Naciones [(alemanes (sajones), húngaros (magiares), szekler y rumanos (valacos y moravos)], recibió con mayor alegría que nosotros la «espada sangrienta» o acudió con mayor presteza al llamamiento guerrero del rey y se puso bajo su estandarte? Y cuando quedó lavada esa gran afrenta de mi patria, la vergüenza de Cossova, y las banderas de los magiares y los volacos sucumbieron ante la Media Luna, ¿quién, sino uno de mi propia estirpe, fue el que cruzó el Danubio como vaivoda y venció al Turco en su propio terreno?. ¡Por supuesto que fue un Drácula! (...) ¿Acaso no fue aquel mismo Drácula [( Mihai Viteazul o Miguel el Bravo)], quien, decidido a romper con el pasado y unirse a la Cruzada, logró invadir territorio turco en 1594, apoderándose de varias fortalezas situadas a orillas del Danubio., en efecto, quien legó su ardor patriótico a otros de sus descendientes, el cual, en época posterior, cruzó repetidamente el gran río con sus tropas para invadir Turquía, volviendo una y otra vez pese a ser rechazado, porque sabía que, aunque regresara solo del ensangrentado campo de batalla donde habían sucumbido los suyos, al fin triunfaría? (...) Y una vez más, cuando tras la batalla de Mohács nos sacudimos el yugo húngaro, nosotros los Drácula estuvimos entre sus jefes, pues nuestro espíritu no soportaba la falta de libertad. ¡Ah, mi joven caballero!, los szekler —y los Drácula siempre fueron su sangre, su cerebro y su espada - pueden vanagloriarse de un historial que los Habsburgo y los Romanoff, pese a haberse multiplicado como hongos, jamás podrían igualar (Stoker, 1993: 137-140). ${ }^{11}$

11. Aunque Stoker se sirvió de ciertos aspectos de la vida de Vlad III para dar vida a su personaje ficticio, la conexión entre ambas entidades es más imprecisa. Numerosas son las leyendas que se ciernen en torno a la figura del príncipe Vlad III, pero lo que si es cierto es que, mientras que este fue un temible sanguinario para sus enemigos (turcos, sajones y rusos), para los rumanos fue todo un héroe. Pese a sus métodos sanguinarios, en ninguna de las leyendas se le acusa de vampirismo, ni tan siquiera de prácticas satánicas o exotéricas. "Como Gabriel Ronay descubrió en 1956, el único vampiro histórico 
La primera descripción física del conde nos llega por medio del narrador homodiegético, Jonathan Harker, quien describe a un cochero «de elevada estatura, con una larga barba de color castaño y un gran sombrero negro que le ocultaba el rostro. (...) ojos muy brillantes, (...) [y] rojos. Aunque sonreía al hablar, (...) la expresión de su boca era dura, con labios muy rojos y dientes afilados, tan blancos como el marfil» (Stoker, 1993: 110-111).

En el castillo, el personaje-narrador realiza un perfecto retrato del conde. Estas descripciones del conde corresponden a su aspecto más maduro, donde Drácula es presentado como una «persona» de avanzada edad, pero extrañamente fuerte:

Apareció ante mí un anciano de elevada estatura, pulcramente afeitado a excepción de un gran bigote cano, y vestido completamente de negro. (...) El anciano me indicó que entrase con un gesto cortés de su mano derecha, diciendo en excelente inglés, aunque con un extraño acento:

— ¡Bienvenido a mi casa! ¡Entre libremente y por su propia voluntad! ${ }^{12}$

(...) tendiéndome la mano, apretó la mía con tal fuerza que me hizo estremecer de dolor, sensación que no disminuyó por el hecho de que estuviera tan fría como el hielo y más bien pareciera la mano de un muerto (Stoker, 1993: 117-118).

Según se aproxima al conde, Harker, desde su visión de narrador testimonial, ofrece un retrato minucioso del rostro y las manos de Drácula, quien muestra una fisonomía de rasgos muy acusados:

Su rostro era marcadamente aguileño, de nariz delgada con el puente muy alto y las aletas arqueadas de una forma peculiar; la frente era alta y abombada y los

del que queda constancia en Transilvania fue una mujer: la condesa Erzsébet Báthory, (...) que vivió al pie de los Cárpatos un siglo después que Vlad y fue emparedada en su propio castillo por matar a más de 600 doncellas para bañarse en su sangre. Stoker podría haber tenido noticias de su existencia, ya que su caso se cita brevemente en (...) Book of the Were-wolves» (Molina, 1993: 35). También es cierto que en ninguna parte del relato se hace referencia a las atrocidades que hicieron famoso a Vlad y que le dieron el sobrenombre de Tepes. Otro aspecto importante a tener en cuenta es que el autor llama a su protagonista conde Drácula y no príncipe Drácula. El hecho de que Stoker hiciese uso de ciertos datos biográficos de Vlad III no demuestra que el autor pensase en convertir a su personaje ficticio en el resurgimiento del príncipe vaivoda. El escritor simplemente utilizaría los datos de los que tenía conocimiento porque los consideró adecuados para completar la vida pasada de su protagonista y justificar sus acciones presentes en el relato (Gubern y Carós, 1979: 49). Con toda la información bibliográfica que el autor utiliza, este le otorga a Drácula un pasado glorioso, de modo que todo adquiere una nueva dimensión. Se trata pues de una figura histórica con un alto rango militar, procedente de una poderosa estirpe, los Dracul. Además remarcó su aspecto más valiente y guerrero, concediéndole un árbol genealógico insigne.

12. Esta invitación con la que el conde recibe al señor Harker era una fórmula frecuente en los países centroeuropeos. La invitación a entrar libremente y por propia voluntad ya aparecía en el clásico alemán «The Mysterious Stranger», en el cual existen ciertas similitudes con Drácula, como el consabido vampiro aristócrata, la zona montañosa de los Cárpatos y el castillo en ruinas. 
cabellos, escasos en las sienes, eran abundantes en el resto de la cabeza. Sus cejas, muy pobladas, casi se unían por encima de la nariz y eran tan espesas que parecían rizarse por su misma abundancia. La boca, a juzgar por lo que se podía ver bajo el grueso bigote, era firme y más bien cruel, y sus dientes, particularmente blancos y afilados, sobresalían de los labios, cuya rubicundez denotaba una vitalidad asombrosa para un hombre de su edad. Por lo demás, sus orejas eran pálidas y extremadamente puntiagudas; el mentón era ancho y fuerte, y las mejillas firmes, aunque hundidas. La impresión general que daba era de una palidez extraordinaria. Hasta entonces sólo me había fijado en el dorso de sus manos, apoyadas sobre las rodillas, y a la luz de la lumbre me habían parecido blancas y finas. Pero al verlas de cerca pude comprobar que eran bastas, con dedos cortos y gruesos. Y por extraño que pueda parecer, había bello en el centro de las palmas. Las uñas eran largas y finas, y estaban afiladas. Al inclinarse hacia mí y rozarme sus manos, no puede reprimir un escalofrío. Tal vez fuese la fetidez de su aliento ${ }^{13}$ (Stoker, 1993: 120-121). ${ }^{14}$

La última descripción física de Drácula es realizada por Mina Harker (narrador homodiegético/testimonial), quien nos describe a «un hombre alto y delgado, con una nariz ganchuda, bigote negro y barba puntiaguda, que (...) observaba a la preciosa joven. (...) tenía facciones duras, crueles, sensuales, y sus dientes, grandes y blancos, que parecían más blancos todavía porque sus labios eran muy rojos, estaban afilados como los de un animal» (Stoker, 1993: 336).

Es innegable que el conde Drácula debe mucho al vampiro polidoriano de aristócrata aciago y cruel, buenos modales, mirada penetrante, extremadamente fuerte e irresistiblemente atractivo para las jovencitas. No obstante, Stoker transforma su apariencia externa y lo aproxima más al vampiro tipo

13. El aliento fétido, junto al aspecto físico del vampiro stokeriano, proviene más bien del folclore de los hombres-lobo. Esta información ya aparecía en The Book of Were-wolves, uno de los cuarenta títulos que consultó el escritor para su Drácula, y que podemos consultar en el volumen II de las Notes.

14. Atendiendo a esta descripción fisonómica, es destacable la influencia del trabajo del famoso psiquiatra y antropólogo italiano Cesare Lombroso, L'uomo delinquente (1876), donde retrató el perfil de lo que definió como el «criminal nato». El perfil creado por Lombroso serviría para identificar a aquel que genéticamente estaba destinado a seguir el camino de los desviados (o los degenerados) y actuar antes de que cometiera algún crimen. Estas características prototípicas del rostro de un criminal se resumen en: baja capacidad craneal, frente despejada, cráneo braquicéfalo, pelo crespo y largas orejas; características que sin duda Stoker plasmó perfectamente en su descripción fisonómica de Drácula. Junto a Lombroso, también aparece en la novela el nombre del médico y escritor húngaro Max Nordau (Stoker, 1993: 575), quien adoptó en su trabajo, Entartung (1892), los puntos de vista de Lombroso acerca de la degeneración. Nordau estableció una relación entre el temperamento y la degeneración moral. Tanto Lombroso como Nordau afirmaron que unas personas eran más primarias y mostraban de manera más abierta su naturaleza deshumanizada que otras. Según expresó Lombroso, la descripción tipológica criminal «desire[s] not only to extinguish life in the victim, but to mutilate the corpse, tear its flesh and drink its blood» (en Lombroso-Ferrero, 1911: xxv, citado en Sánchez-Verdejo, 2011: 526). El conde es, de acuerdo con Mina (Stoker, 1993: 575), «un criminal, del tipo criminal»: «his ability to change the lives and identities of those whom he encounters recalls how crime becomes, at the fin de siècle, as much as medical problem as a moral issue» (Hughes, 2009: 7). 
Varney: elevada estatura, rostro cetrino, nariz aguileña, colmillos prominentes, capa negra, etc.

En la novela, también aparece el análogo femenino del vampiro: la vampiresa, quien es subyugada a este tirano del mal. El tratamiento fisonómico de las tres vampiresas del castillo es similar al de Drácula: ${ }^{15}$

Dos de ellas eran morenas, tenían larga nariz aguileña como el conde, y grandes y penetrantes ojos oscuros, que parecían casi rojos en contraste con la palidez amarillenta de la luna. La otra era de tez clara, extremadamente clara, con abundante y ondulado pelo rubio y ojos como pálidos zafiros. (...) Las tres tenían los dientes blancos y relucientes, que brillaban como perlas sobre el rubí de sus labios voluptuosos (Stoker, 1897: 150). ${ }^{16}$

Los narradores homodiegéticos describen a las vampiresas como bellas y letales. Incluso la dulce Lucy Westenra, al convertirse en vampiro, se torna más bella, pero deja atrás esa dulzura que la caracterizaba para dar paso a una versión diabólica y sanguinaria que es incluso capaz de raptar niños para alimentarse y atacar a su prometido, Arthur Holmwood.

Esta femme fatale causa la desgracia de cualquiera que se cruce en su camino. En su trabajo sobre las muertas en la literatura y el cine, Pilar Pedraza (2004) le otorga un puesto relevante a la figura de la mujer vampiro, recordando, en primer lugar, la figura mitológica de Empusa, quien es capaz de metamorfosearse en diferentes animales o en mujeres que succionan la sangre de los jóvenes para mantenerse longevas. Miriam López Santos (2008: 200) ase-

15. En Macbeth, el rey vive en un castillo deshabitado junto a tres hermanas misteriosas. Posiblemente, esto pudo servir de inspiración a Stoker, pues sitúa al conde en un viejo castillo de los Cárpatos, junto a tres vampiresas.

16. La descripción física de las vampiresas recuerda a aquella mítica figura del folclore irlandés: la banshee (o Bean Sidhe), de la que seguramente Stoker, por su origen irlandés, tuvo conocimiento. Y es que en Irlanda, un país caracterizado por «an arrestive and wildly beautiful scenery, it is not at all surprising to find something in the nature of a ghost harmonising with the general atmosphere and surroundings, and that something, apparently so natural to Ireland, is the Banshee» (O'Donnell, 2012: 4). La banshee normalmente es un espíritu familiar que regresa de entre los muertos para acosar a las familias del más antiguo linaje irlandés. Por tanto, no es de extrañar que esta criatura se haya llegado a conocer popularmente como un presagio de muerte. Robert Tracy (1999: 13) describe a las banshee «like living men and women, but they are immortal, or at least very long-lived. They have special powers and can employ magic. They seem to enter and leave the mounds freely, but at Halloween the mounds are open all night long, and the sídhe are most powerful and most dangerous». Los escritores góticos irlandeses de los siglos XVIII y XIX retrataron a la banshee como un depredador sexual, cuya característica más prominente es su aullido. Bríana Walsh (2011: 65-68) presenta tres posibles representaciones de esta criatura: a) la Bean Sí, quien es descrita como una mujer joven y hermosa; b) la Bean Chaointe, cuya característica más distintiva es su voz, "[a] woman who cries (...), that is, [a] women hired to mourn for the dead at a funeral», y cuyo aspecto es viejo y horripilante; y c) la Badahbh, quien con frecuencia es representada como un pájaro y quien forma parte del triunvirato de las deidades guerreras del folclore celta. En Drácula, las tres vampiresas que viven junto al conde encarnan a la joven y hermosa Bean Sí. 
gura que esta figura aparece para tentar a los hombres y así evitar el desarrollo de sus espíritus. Su «existencia como posible ser real, pero encerrado en un texto le permite al hombre fantasear durante la lectura, pero sabedor de que podrá seguir dominando el mundo cuando cierre esas páginas» (Sánchez-Verdejo, 2011: 693).

En el castillo, Harker, hombre honesto y fiel, reconoce que se sintió fuertemente atraído por el poder de seducción de las tres vampiresas (Stoker, 1993: 151). Incluso Van Helsing, quien está firmemente dispuesto a acabar con ellas, sucumbe al atractivo de estos voluptuosos y diabólicos seres; situación que origina un estado de fascinación y conmoción en el personaje-narrador:

Sabía que tenía que localizar al menos tres tumbas (...). Busqué y busqué, y encontré una. En ella yacía una de las mujeres durmiendo su sueño de vampiro, tan llena de vida y de voluptuosa belleza, que me estremecí como si hubiese ido a allí a cometer un asesinato. ¡Ah!, estoy seguro que antaño, cuando tales cosas existían, a más de un hombre dispuesto a acometer una tarea como la mía, acabaría por fallarle el valor (...). [La] mera belleza y la fascinación de la sensual no-muerta le hipnotizaría;17 y se quedaría allí obnubilado hasta la llegada del crepúsculo, y la vampira se despertaría. (...) Y como el hombre es débil, se convertiría en una nueva víctima para la grey del vampiro; (...) Sin duda debe existir una cierta fascinación, ya que la sola presencia de semejante ser me conmovió, incluso tendida como estaba en una tumba desgastada por el tiempo y cubierta por el polvo de siglos, y a pesar del terrible hedor que allí reinaba (...). Sí, me sentí conmovido - yo, Van Helsing, a pesar de mi firme propósito y de todos mis motivos para odiarla-, tan conmovido que me vino un deseo irresistible de demorar mi plan, que parecía paralizar mis facultades y entorpecer mi alma (Stoker, 1993: 614-615).

Este poder de atracción y dominio sobre otros personajes no es un rasgo exclusivo de las vampiresas. El conde es capaz de ejercer una influencia mayor sobre el resto de personajes, siendo especialmente vulnerables aquellos que pasan por un momento de estrés o fatiga mental, como Harker durante su estancia en el castillo o Lucy y Mina cuando son acosadas durante la noche, o bien sufren cualquier tipo de trastorno psíquico, como es el caso del zoófago Renfield. Un episodio de la novela donde se celebra el bautismo del vampiro nos recuerda este fuerte poder de influjo; Mina expresa abiertamente su incapacidad para resistirse a los deseos del conde (Stoker, 1993: 500-502). En este bautismo, Drácula establece lazos de unión con Mina a través del in-

17. El hipnotismo es uno de los temas principales de la novela The Witch of Prague que probablemente pudo atraer la atención de Stoker. 
tercambio recíproco de sangre. ${ }^{18}$ Se produce entonces una conexión a nivel físico y mental entre ambas partes. ${ }^{19}$

En la novela tampoco pasan inadvertidas las habilidades físicas del vampiro: tiene una fuerza y una velocidad extraordinarias; posee una agudeza visual que le permite ver incluso en la oscuridad; puede prolongar su existencia, rejuvenecer y aumentar su vigorosidad gracias a la sangre que succiona de los vivos; ${ }^{20}$ posee el poder de la adivinación mediante la invocación a los muertos (necromancia) y el poder sobre los mismos; puede aparecerse a voluntad, adoptar cualquier forma (un lobo y un murciélago), cambiar de tamaña e incluso desvanecerse; tiene el poder de mandar sobre los elementos (la tempestad, la niebla y el trueno); ejerce poder sobre las criaturas oscuras (la rata, el búho, el murciélago, el lobo, ${ }^{21}$ etc.); su cuerpo no proyecta sombras, ni su imagen se refleja en un espejo; ${ }^{22}$ puede llegar envuelto en niebla que él mismo crea (aunque el alcance de esa niebla es limitado, lo suficiente para rodearlo); y es capaz de aparecer en los rayos de la luna, en forma de minúsculas motas de polvo (Stoker, 1993: 428-432).

Pese a todas estas capacidades sobrenaturales, el vampiro también posee puntos débiles: no puede entrar en ningún hogar habitado si alguien de dentro no le ha invitado a pasar (aunque después puede regresar cuando le plazca); aunque puede caminar a la luz del día, su poder se ve seriamente

18. Stoker hizo uso de varios artificios de Varney, los cuales hizo suyos, los desarrolló completamente e incluso los transformó, e.g., la iniciación de la heroína a través de la sangre, la atracción/repulsión que ejercen los vampiros sobre sus víctimas, etc. Otra posible lectura de la novela la convierte en una especie de alegoría cristiana donde se produce una lucha eterna entre Cristo (la luz) y Satanás (la oscuridad). En la escena del bautismo del vampiro, la imagen de Cristo es parodiada por Drácula, quien promete la resurrección y la inmortalidad al beber su sangre porque «iLa sangre es vida! ¡La sangre es vida!» (Stoker, 1993: 296), aunque la vida eterna sea una corporeidad animada con olor a muerte. El obsceno episodio del sacramento de la Eucaristía en la que Drácula se abre una vena en el pecho y fuerza a Mina a beber de ella alude a la particular visión acerca del pelícano; al observar cómo este animal alimentaba a sus crías, los antiguos imaginaron al pelícano alimentando a sus crías con sangre, para lo cual se abría el buche a picotazos. En la iconografía cristiana de la Edad Media, el pelícano es una alegoría de Cristo, quien derrama su propia sangre para la salvación de la humanidad.

19. Ciertos componentes de «Carmilla» también son reconocibles en la novela de Stoker, e.g., la seducción de Lucy o de las novias de Drácula a sus víctimas. Se evoca a la protagonista de Le Fanu, Carmilla, cuya extraña relación amor/odio con Laura parece trasplantada (desprovista de su ambigüedad sexual) a la intimidad, no solo física sino también mental, entre Mina y Drácula.

20. La succión de sangre, dentro de la literatura, para aumentar la longevidad, juventud y vigorosidad de un vampiro ya aparecía en relatos como «El vampiro», "La muerta enamorada» o La rama dorada. Para un análisis detallado sobre «El poder mágico de la sangre», véase el exitoso trabajo de Agustín Calmet (2009) y la tesis doctoral de Francisco Sánchez-Verdejo (2011).

21. Al inicio del relato, Harker, narrador testimonial, presencia, en su viaje al castillo del conde, cómo los lobos obedecen al extraño cochero de la calesa (Stoker, 1993: 115). Este episodio del hombre misterioso que calma a los lobos ya aparecía en el clásico alemán «The Mysterious Stranger».

22. El reflejo o la sombra como símbolos del alma, que el vampiro ha perdido, han sido tomados de la tradición germánica. 
mermado; ${ }^{23}$ debe descansar en tierra de su país natal, por lo que necesita trasladarla; no puede cruzar aguas en movimiento; algunas cosas, como el ajo y ciertos objetos sagrados, como un crucifijo, anulan su poder; una rama de rosal silvestre puesta sobre su ataúd le impide abandonarlo; ${ }^{24} \mathrm{y}$, finalmente, una bala consagrada disparada contra el ataúd o una estaca atravesándole el pecho y la decapitación le proporcionan la verdadera muerte (Stoker, 1993: 432-433). ${ }^{25}$

Con respecto a las habilidades del conde antes citadas, es destacable el poder de Drácula para metamorfosearse en varios animales. Para ello, el autor recurre a la técnica de caracterización conocida como animalización que, ligada a la cosificación (más adelante explicada), consiste en atribuir una serie de rasgos o cualidades propias de los animales a los seres humanos. A pesar de que el conde realmente ya no es un ser humano, un vistazo general a las descripciones fisonómicas antes expuestas nos revela que sí se asemeja físicamente a una persona, aunque con las diferencias notables que los personajes-narradores remarcan, como colmillos prominentes, orejas puntiagudas y ojos rojos. La animalización puede "presentar dos variantes: una, el personaje transfigura de forma abrupta y total su apariencia, (...), o, en segundo término, se limita esta atribución de bestialidad o de mera deshumanización al comportamiento desnaturalizado de un personaje» (Álamo, 2006: 206). Ambas variantes están presentes en la novela, pues Drácula es capaz de transformarse en lobo, al llegar el barco fantasma a Whitby, y en murciélago, como lo vieron Mina y Morris en la ventana de la casa de Lucy, pero también se comporta como un auténtico monstruo. El pasaje del conde reptando por el muro del castillo plasma a la perfección el proceso de bestialización del conde Drácula:

mis sentimientos se trocaron en repugnancia y terror cuando vi que el conde salía lentamente por la ventana y empezaba a reptar, cabeza abajo, por el muro del castillo hacia aquel espantoso abismo, con la capa extendida en torno suyo como unas grandes alas. (...) Vi cómo los dedos de sus manos y de sus pies se aferraban a los cantos de las piedras, desprovistos ya de mortero por el paso del tiempo, utilizando así los salientes y desigualdades para descender a velo-

23. La característica del vampiro caminando a luz del día tiene su origen en algunos vampiros folclóricos, como el vampiro del folclore griego, el Vrykolakas o brucolaco. Julio A. Olivares Merino (2001: 506) destaca que la idea de que la luz del día pudiera matar a un vampiro apareció por primera vez en Nosferatu (1922), de Friedrich W. Murnau.

24. Así como sucede con el vampiro búlgaro, el krvopijac.

25. En «The Mysterious Stranger», la escena donde Franziska le atraviesa el corazón al extraño misterioso, un vampiro, con un enorme clavo mientras el conde Woislaw recita el credo en voz alta, es similar al pasaje en el que lord Godalming se ve obligado a clavarle una estaca a Lucy para librarla de la maldición de ser vampiro, mientras Van Helsing recita su misal (Stoker, 1993: 399). 
cidad considerable, igual que un lagarto se desliza a lo largo de un muro (Stoker, 1993: 145-146).

Es importante destacar que la monstruosidad de Drácula es ambigua, pues no siempre es reconocida como tal (recordemos la amabilidad que muestra al señor Harker antes de casi destruirlo). Tras la fachada de «persona» afable, el vampiro stokeriano, figura trágica y símbolo de pura maldad, realmente se comporta como un depredador: observa, embelesa y ataca. Después del desgaste psíquico, da paso al ataque físico. Incluso Harker se da cuenta del extraño comportamiento del conde, inusual en un hombre de su posición (Stoker, 1993: 121).

Es importante destacar que el tema de la transfiguración en la caracterización de Drácula es bastante complejo, pues saca a debate las siguientes cuestiones: ¿es Drácula un «ser humano» capaz de transformarse en varios animales (animalización)? ¿O, por el contrario, es Drácula un animal (un monstruo) capaz de adquirir ciertos atributos, rasgos y capacidades humanas (antropomorfo)? Ambas cuestiones ya las planteó Stoker (1993: 146), quien, a través de su narrador homodiegético, el señor Harker, cuestiona la auténtica naturaleza de Drácula: «¿Qué clase de hombre es este [(animalización)], o qué clase de criatura con apariencia de hombre [(antropomorfo $)]$ ?». ${ }^{26}$

Ligada a la animalización, nos encontramos la cosificación. Este proceso se presenta bien mediante el modelo de la

hiperdescripción objetual (...) [o el modelo del] (...) proceso narrativo degradador y/o caricaturesco de objetualización de determinados actores antropomórficos a partir de la pérdida de sus atributos más humanos y personales. Se relaciona así normalmente con determinados procesos de animalización o con la propia degradación psicomoral de ciertos individuos que pierden sus valores humanos, como ocurre con ciertas figuras novelescas como algunos dictadores (Valles y Álamo, 2002: 275-276).

En Drácula, la cosificación se presenta mediante el segundo modelo descrito; el proceso de animalización o bestialización del conde antes descrita ejemplificaría este tipo de cosificación.

26. Ambas opciones son igualmente válidas, dependiendo de la postura que se desee adoptar: a) Drácula conserva parte de su aspecto humano de antaño, pero su carácter es más monstruoso, vil y aniquilador, capaz incluso de llegar a metamorfosear su apariencia externa, transformándose en un auténtico monstruo o animal (animalización); b) Drácula en realidad es un monstruo, que se transforma y adopta rasgos, atributos y capacidades humanas (antropomorfo) para lograr diversos fines, como, por ejemplo, engañar a sus adversarios. 
Como hemos podido observar por medio del análisis anterior, el conde Drácula aparece bajo diferentes guisas a lo largo de la novela, gracias a su capacidad para transformarse. Finalmente, hemos de destacar que gran autoridad ha tenido, sobre todo por su uso frecuente en las historias góticas y de ciencia ficción, esta técnica de caracterización: la transfiguración (o morphing), que consiste en modificar el conjunto fisonómico de un personaje en otro distinto a lo largo del relato, así como sucede con el conde Drácula a lo largo del relato y que hemos podido exponer en este artículo.

\section{CONCLUSIONes}

En líneas generales, este artículo nos ha proporcionado una interesante síntesis sobre el proceso de construcción del personaje vampírico. Es más, es, desde esta perspectiva narratológica, por medio del análisis pormenorizado de los distintos elementos narrativos aquí expuestos, que reconduciendo el mito de Drácula, en el que se funden, se acomodan o se inventan los orígenes de la leyenda y las fuentes y tradiciones literarias de la novela de Stoker, junto a las considerables reinterpretaciones que la figura del conde ofrece, como puede enfrentarse/entenderse su complejidad interna y significativa. Ordenar y explicar dichos elementos e intentar, aquí está la clave, descifrar el peculiar proceso de construcción del personaje nos ha servido para su correcta interpretación y comprensión.

\section{BiBLIOGRAFÍA}

Álamo Felices, Francisco D. (2006): «La caracterización del personaje novelesco: perspectivas narratológicas», Signa. Revista de la Asociación Española de Semiótica, vol. 15, pp. 189-213, disponible en <dialnet.unirioja.es/servlet/fichero_articulo?codigo $=1455777>$ [fecha de consulta: 14/7/2015].

(2010): «Introducción a la estructura y composición narrotológica del Drácula de Bram Stoker», lectura en el curso ¿Cuándo se le rompió el espejo al Vampiro? El Mito del Vampiro a través del arte, la ciencia y la cultura, organizado por la Fundación Empresa Universidad de Granada y la Facultad de Filosofía y Letras, Granada.

BERESFORD, Mathew (2008): From Demons to Dracula: The Creation of the Modern Vampire Myth, Reaktion, Londres.

Calmet, Agustín (2009): Tratado sobre los Vampiros, Lorenzo Martín de Burgo (trad.), Luis Alberto de Cuenca (pról.), Reino de Cordelia, Madrid.

CRÉMÉNÉ, Adrien (1981): Mythologie du vampire en Roumanie, Rocher, Paris. 
Ducrot, Oswald, y Jean-Marie Schaeffer (1998): Nuevo diccionario enciclopédico de las ciencias del lenguaje, Arrecife, Madrid.

Eighteen-BisAng, Robert, y Elizabeth Miller (2008): Bram Stoker's Notes for Dracula, McFarland \& Company, Jefferson, North Carolina y Londres.

Florescu, Radu R., y Matei Cazacu (2013): Dracula's Bloodline: A Florescu Family Saga, Hamilton Books, Nueva York.

Frayling, Christopher (1991): Vampyres: Lord Byron to Count Dracula, Faber \& Faber, Londres.

Garrido Domínguez, Antonio (1996): El texto narrativo, Síntesis, Madrid.

Gubern, Román, y Joan P. Carós (1979): Las raíces del miedo. Antropología del cine de terror, Tusquets, Barcelona.

GuILEY, Rosemary (2005): The Encyclopedia of Vampires, Werewolves, and Other Monsters, Facts On File, Nueva York.

Hughes, William (2009): Bram Stoker's Dracula: a reader's guide, Continuum, Londres \& Nueva York. <https:/ /doi.org/10.5040/9781474211277>

López Santos, Miriam (2008): «Teoría de la novela gótica», E. H. Filología, núm. 30, pp. 187-210, disponible en <http:/ / tinyurl.com/ku3jbdz> [fecha de consulta: 21/9/2015]. <https://doi.org/10.18002/ehf.v0i30.2840>

Ludlam, Harry (1962): A Biography of Dracula, W. Foulsham \& Co., Londres.

Marchese, Angelo y, Joaquín Forradellas (1986): Diccionario de retórica, crítica y terminología literaria, Ariel, Barcelona.

MolinA Foix, Juan A. (1993): «Introducción», en Bram Stoker, Drácula, Cátedra, Madrid, pp. 9-90.

O'Donnell, Elliot (2012): The Banshee, The Floating, Auckland.

Olivares Merino, Julio A. (2001): Cenizas del plenilunio alado: pálpitos y vestigios del vampiro en la literatura inglesa anterior a «Dracula» de Bram Stoker: tradición literaria y folclórica, Universidad de Jaén, Jaén.

Pedraza, Pilar (2004): Espectra. Descenso a las criptas de la literatura y el cine, Valdemar, Madrid.

RanK, Otto (1976): El doble, Orión, Buenos Aires.

ReIs, Carlos (1996): Diccionario de narratología, Colegio de España, Salamanca.

Rodríguez, Juan C. (1986): «Otra vez el diablo. La escritura del mal o la otra cara del criticismo. Sobre Borges, murciélagos y espejos», Olvidos de Granada, núm. 14, pp. 13-18.

SÁnchez-Verdejo Pérez, Francisco J. (2011): Terror y placer: hacia una (re)construcción cultural del mito del vampiro y su proyección sobre lo femenino en la literatura escrita en lengua inglesa, Ediciones de la Universidad de Castilla-La Mancha, Cuenca, disponible en <https://ruidera.uclm.es/xmlui/handle/10578/1197> [fecha de consulta: 14-6-2016].

SKAL, David J. (2006): Vampires: Encounters with the Undead, Black Dog \& Leventhal, Nueva York.

Stoker, B. (1993): Drácula, trad. J. A. Molina Foix, Cátedra, Madrid.

Summers, Montage (1960): The Vampire: His Kith and Kin, University Books, Nueva York. 
Todorov, Tzvetan (1975): The Fantastic: A Structural Approach to a Literary Genre, trad. Richard Howard, Cornell UP, Nueva York.

Tomashevski, Boris (1978): «Temática», en Tzvetan Todorov (ed.), Teoría de la literatura de los formalistas rusos, Siglo Veintiuno, México, pp. 199-232.

Tracy, Robert (1999): «Undead, Unburied: Anglo-Ireland and the Predatory Past», LIT: Literature Interpretation Theory, vol. 10, núm. 1, pp. 13-33. <https://doi. org/10.1080/10436929908580232>

Valles Calatrava, José R. (2008): Teoría de la narrativa: una perspectiva sistemática, Iberoamericana, Madrid.

Valles Calatrava, José R., y Francisco D. Álamo Felices (2002): Diccionario de teoría de la narrativa, Alhulia. Granada.

Walsh, Bríana (2011): Irish Female Gothic Fiction: A Study of the Fiction of Regina Maria Roche and Sydney Owenson [tesis doctoral], disponible en <http:/ / tinyurl.com/ ppyc4js> [fecha de consulta: 23/9/2015]. 
